\title{
Correlates of Pedestrian and Cyclist Falls in Snowy and Icy Conditions
}

\author{
MARTIN BÄRWOLFF ${ }^{\mathrm{a}}$, ANGELIKA REINARTZ ${ }^{\mathrm{b}}$, REGINE GERIKE $^{\mathrm{a}}$ \\ a. TU Dresden, Professur für Integrierte Verkehrsplanung und Straßenverkehrstechnik, Dresden, 01069, Germany \\ b. BSV Büro für Stadt- und Verkehrsplanung Dr.-Ing. Reinhold Baier GmbH, Hanbrucher Str. 9, Aachen, 52064, Germany
}

KEYWORDS: Pedestrian Falls, Cyclist Falls, Cycling Speed, Snow, Winter Maintenance

ABSTRACT: Existing international studies consistently report increased numbers of pedestrian and cyclist falls in the winter months, particularly in icy/snowy conditions. Until now, reliable information on the factors contributing to these falls has been rare.

This study investigates possible correlates of pedestrian and cyclist falls in icy/snowy conditions in Germany and takes into consideration factors such as behavior and surface conditions with the aim to develop recommendations for improving safety for vulnerable road users.

As part of this study, 3,300 people in online surveys and 2,100 in field surveys were asked about their experiences and opinions in relation to icy/snowy conditions and winter maintenance. Of those surveyed, 1,100 pedestrians and 2,200 cyclists also reported details about their most recent fall within the last five years. Furthermore, the behavior of 7,000 pedestrians and 4,500 cyclists was observed with cameras in both snowy and other weather conditions.

The presence of snow/ice itself was indicated as a reason for three quarters of pedestrian and two thirds of cyclist falls in snowy/icy conditions. For nearly all of the falls in snowy/icy conditions, surfaces were reported as poorly cleared or not cleared at all. Compared to other weather more pedestrians fell on sidewalks and less while crossing the street during snowy and icy conditions.

Cyclists increased their speed on downhill sidewalks in dry conditions and reduced their speed in snowy conditions compared to flat or uphill sidewalks. Most cyclists chose to cycle on sidewalks instead of their own dedicated, but not maintained, facilities (even though they are obliged by law to cycle on the carriageway in such cases). In snowy/icy conditions, $5 \%$ of pedestrians varied their pace or step sequence and $8 \%$ of cyclists drove "wavy lines" or made obvious corrective steering movements, particularly on poorly maintained facilities (compared to very few of such observations in other weather conditions).

Half of the respondents rated the winter maintenance at pedestrian facilities to be good and three quarters rated the maintenance at public transport stops as good. In contrast, only $12 \%$ rated winter maintenance on cycling facilities as good. Reasons for not being satisfied included poor quality, delay and insufficient frequency of cleaning as well as the type of grit used. The lack of seamless reliably-cleaned cycle routes was listed as a major problem by most respondents. More than $50 \%$ claimed that previously cleaned pedestrian or cyclist facilities were re-covered with snow from clearing the carriageway.

\section{INTRODUCTION}

Walking and cycling as means of active mobility support sustainable transport systems. They are environmentally friendly, inclusive, inexpensive, flexible, space efficient and improve public health thanks to the physical activity related to active mobility (Koszowski et al., 2019). Walking and cycling should therefore be promoted throughout the year. Particularly in winter time in snowy and icy conditions, high quality facilities for pedestrians and cyclists are a precondition for encouraging people to walk and to cycle and for minimizing risks to fall or to get involved into an accident.

Much effort goes into winter road safety of Motorized Individual Transport, e.g. by comprehensive research, organized and differentiated winter maintenance, permission to apply road salt and obligation to use winter tires. Significantly less effort has been spent on investigating correlates of pedestrian and cyclist road safety and on strategies for safety improvement for these user groups in snowy/icy conditions. This is at least partly because pedestrian and bicyclist falls are not considered a major safety problem in society, with the true extent hidden by the non-recording of pedestrian falls and the underreporting of single bicycle crashes to official accident databases (Methorst et al., 2017). Along with this comes the fact, that the causes and correlates of these falls are hardly known so far and can only be investigated with great effort.
For example, not much evidence exists on how winter conditions, as well as winter maintenance, affect risks of falls, route choice, and speeds of pedestrians and cyclists. Furthermore, pedestrians and cyclists can also improve their safety by using appropriate equipment such as spiked tires or studs for their footwear. But there are hardly any studies known on the extent to which this equipment is actually used by the population in winter conditions and how often falls still occur.

In this paper we analyze the circumstances and contributing factors of pedestrian and cyclist falls and the associated adaptations in small-scale behavior as well as opinions on winter maintenance.

\section{LITERATURE REVIEW}

A review is carried out on existing studies which analyzed direct correlates of pedestrian and cyclist falls as outcomes, like the influence of road user's equipment and surface conditions on fall statistics and slipping probability. We also have a look on studies about how pedestrians and cyclists have adapted their traffic behavior to winter conditions so far and here, focus on small-scale adaptations. Furthermore, we highlight studies aimed at surveying the public opinion on winter maintenance on walking and cycling facilities. 


\subsection{Correlates of pedestrian and cyclist falls}

\subsubsection{Road user equipment}

Gard and Lundborg (2000) interviewed four persons who completed test walks with various anti-skid devices on untreated winter surfaces (ice, snow) as well as on treated winter surfaces (with gravel, sand, salt). They noticed hardly any differences in the perceived walking safety between the device types (forefoot, heel, whole foot), but large differences between the specific products. Larsson, Berggård, Rosander, and Gard (2019) did similar test walks with 19 participants on untreated winter surfaces (ice, ice covered with snow), but also measured walking speeds. Like Gard and Lundborg (2000) they found, that perception of walking safety depends on the specific anti-skid product. Further, they found that participant's safety and balance ratings correlated with their measured comfortable walking speeds.

Bach and Böhm (1994) found during on-site surveys in winter conditions that less than half of the respondents wore footwear suitable for the weather conditions. Exclusively among older respondents this proportion was higher. In addition, pedestrians were unwilling to accept detours to increase their safety - this observation is consistent with the findings of Muraleetharan, Meguro, Adachi, Hagiwar, and Kagaya (2005). Some pedestrians also noted that they were more likely to walk on the edge on untreated snow than on the cleared snow, which they felt was more compressed and slippery.

Bonander and Holmberg (2019) gave a free pair of studded shoes to older people (65+) and noticed reductions of falls on snow and ice of among these persons in first year after.

Abovementioned studies address anti-skid devices or shoes with built-in studs. So far, only one study by Hsu et al. (2016) could be found on comparing conventional shoes, winter boots and studded footwear in winter conditions. They compared friction coefficient and maximum achievable walking angles in icy conditions for a running shoe, an indoor slip-resistant shoe and several winter boots. While all winter boots achieved slightly better results, only one of them, a boot without a tread pattern but with a special sole material, outperformed all other shoes.

A rather unconventional approach using socks over shoes was tested with promising results by Parkin, Williams, and Priest (2009), who found an improvement in self-reported slipperiness if 0.4 to 2.3 on a 5 -point-scale.

Despite the usage of winter tires with studs is common in northern European countries and proposed by some authors (e.g. Nyberg, Björnstig, \& Bygren, 1996), no studies on usage rates or their ability to prevent cyclist falls in snowy and icy conditions have been found.

\subsubsection{Surface conditions}

Bach and Böhm (1994) conducted an on-site survey of 237 respondents at pedestrian crossings in Dessau and VillingenSchwenningen on falls in snow and icy conditions, in which ice was rated as more dangerous than snow.

Öberg, Nilsson, Velin, and Wretling (1996) analyzed falls of 1,000 pedestrians and cyclists in a hospital study. In this study, $78 \%$ of the injured pedestrians and cyclists considered the condition of the road or sidewalk surface to be relevant to the accident; the majority referred to slippery winter roads in this context.

As described above, Gard and Lundborg (2000) confirm the impact of certain anti-skid devices for the perception of walking safety in winter conditions. However, the surface conditions had an even greater influence on the perceived walking safety in their study. Walking on treated winter surfaces was perceived to be safer than on untreated winter surfaces. The combination of treatment with gravel or sand with the wearing of heel devices was perceived to be the safest.
Abeysekera and Gao (2001) investigated test runs of 25 persons on an icy surface without and with different gritting agents. It was observed that the number of falls or near falls was reduced to one third if the ice was covered with a snow layer of three to five millimeters. The use of gravel and salt further reduced the risk of falls slightly. However, sand proved to be a particularly good gritting material, with almost no more falls or near falls observed.

Ruotsalainen, Ruuhela, and Kanas (2004) contrasted pedestrian slip accidents with weather data and observed that the number of pedestrian falls increased primarily when average daily temperatures were slightly below freezing point.

A survey conducted by Furian, Kühnelt-Leddhin, and Bauer (2011) among pedestrians who had fallen revealed the insufficient condition of the surface due to snow, ice and slush as the most frequent cause of accidents among all accidents throughout the year. In this respect, the authors see a high potential in accident (cost) prevention through efficient winter road maintenance.

Möller, Wallman, and Gregersen (2013) investigated the number of pedestrian falls in Skellefteå (Sweden) before and after improvements of the local winter road maintenance. They observed a $57 \%$ increase in the number of accidents. This unexpected result led them to conclude that improved winter road maintenance does not always improve road safety for pedestrians and cyclists, as better surface conditions in winter are also associated with more careless movement. In addition, snow removal can lead to even poorer skid resistance due to compression. Elvik (2000) also concludes that while cleared sidewalks increase perceived safety for pedestrians, they do not necessarily increase objective safety.

In their study, Nyberg et al. (1996) asked cyclists who had been involved in accidents about the cause of the accident and the influence of the surface condition. The factor "poor maintenance", which includes surfaces that are not cleared, icy or covered with snow, was the most frequently cited influencing factor leading to injuries, at $51 \%$.

In on-site surveys of cyclists on cycling paths in Cologne and Berlin, approx. $5 \%$ to $10 \%$ of the respondents stated that they had already experienced a dangerous situation as a result of poor weather or lighting conditions (Alrutz, Bohle, Müller, \& Prahlow, 2009).

According to Niska (2011), $70 \%$ of all bicycle traffic accidents in Sweden are single-vehicle accidents, of which about $40 \%$ are related to the maintenance of the traffic system ("maintenance related"). Niska and Eriksson (2013) also showed that the majority of single bicycle accidents due to slipping on snow or ice occur in the morning hours between six and ten o'clock.

During on-site surveys of cyclists in Calgary, Canada by Amiri and Sadeghpour (2014), icy traffic facilities were named as by far the greatest safety risk by nearly two-thirds of respondents.

\subsubsection{Personal experience with winter conditions}

A survey of 70 non-Swedes at the Technical University of Luleå (Sweden) showed that the risk of falling decreases with the length of stay in Sweden - and thus with the time spent adapting to winter conditions (Gao \& Abeysekera, 2004).

\subsection{Behavior adaptation}

\subsubsection{Small-scale route choice}

Muraleetharan et al. (2005) observed small-scale route choice behavior in winter weather in a study area in Sapporo, Japan. There, pedestrians can reach a highly frequented destination by either immediately crossing the carriageway via signalized pedestrian crossing and using the not maintained sidewalk or by remaining on the cleared sidewalk. In surveys conducted in parallel pedestrians stated that they choose their 
route according to the state of clearance of the respective sidewalks. However, the observations showed that almost all pedestrians made their route choice dependent on the predicted waiting time at the pedestrian crossing. During or shortly before the pedestrian clearance time, they almost always used the not maintained route.

Fossum and Ryeng (2019) observed the route choices of pedestrians on a street with identical sidewalks on both sides in Trondheim, Norway. In winter conditions, they were plowing both sides for snow removal, but operated only one side with salt to keep the surface bare. Compared to control counting (overall bare surface conditions), they observed reductions in the share of pedestrian volumes on the no-salt side from $41 \%$ to $34 \%$ when there was a snow layer and to $29 \%$ when there was a snow slush layer. No difference to overall bare surface conditions was observed in black ice conditions on the no-salt side. They concluded, that it is the visibility of surface conditions that made pedestrians choose their route.

Shirgaokar and Gillespie (2016) conducted a survey among 33 cyclists in Edmonton, Canada. The respondents indicated that they would adjust their route choice in snowy or icy conditions. For better conditions, they would accept detours or even spontaneously switch to the carriageway or the sidewalk if the use of the cycle path appeared dangerous or uncomfortable.

Durth, Hiersche, and Lamm (1995) state that on snowy days, bicyclists mainly switch from cycle paths that are not maintained by winter road maintenance services to the adjacent carriageway and sometimes to the sidewalk and continue to use the shortest route they are familiar with.

\subsubsection{Speed of movement}

Gard and Lundborg (2000) found that on average comfortable walking speeds while wearing anti-skid devices are lower on ice (speed: $1,3 \mathrm{~m} / \mathrm{s}$ ) than on ice covered with snow (speed: $1,4 \mathrm{~m} / \mathrm{s})$.

Shintani, Hara, Fukumoto, and Akiyama (2003) measured walking speed of people between 20 and 30 years of age during test walks on a sidewalk. In dry conditions, the mean speed was $1.43 \mathrm{~m} / \mathrm{s}$, while it dropped to an average of $1.14 \mathrm{~m} / \mathrm{s}$ when the sidewalk was icy. The authors recognized that spreading gritting materials $\left(36 \mathrm{~g} / \mathrm{m}^{2}\right)$ increased the speed to about $1.23 \mathrm{~m} / \mathrm{s}$. A large increase in the gritting density to $167 \mathrm{~g} / \mathrm{m}^{2}$ did not significantly increase the measured speeds, nor did the use of anti-slip shoes by the test subjects. The subsequent interviews nevertheless showed that the test subjects felt safer after treatment with gritting materials than with the anti-slip shoes.

Weidmann (1992) summarizes the results of several studies on walking speeds of pedestrians. He found that they walk faster as the temperature decreases and that a slope has an accelerating effect only at low rates of ascent. In addition, men walk significantly faster than women $(1.27 \mathrm{~m} / \mathrm{s})$ with an average of $1.41 \mathrm{~m} / \mathrm{s}$, and persons aged between 10 and 60 years walk significantly faster than all other persons. Furthermore, walking speeds are highly dependent on the purpose of the walk. Weidmann estimates that walking speeds on work routes are up to one third higher than on leisure routes. Weidmann (1992) also stated that crossing a carriageway leads to a slight reduction in speed.

Gupta, Li, and Fernie (2008) measured walking speeds on a sidewalk in Toronto, Canada and found a negative correlation between temperatures and walking speeds (means of 1.43 to $1.44 \mathrm{~m} / \mathrm{s}$ below $-5^{\circ} \mathrm{C}, 1.35 \mathrm{~m} / \mathrm{s}$ at $5^{\circ} \mathrm{C}$ and 1.23 to $1.28 \mathrm{~m} / \mathrm{s}$ above $\left.15^{\circ} \mathrm{C}\right)$.

Li and Fernie (2010) observed a signalized pedestrian crossing at a major intersection in Toronto (Canada) at several days within one year under different weather conditions. They found significantly increased impatience and disregard for traffic rules in poor compared to good weather conditions. Walking speed increases significantly in cold temperatures, but this effect was not observed in snow.

Liang, Leng, Yuan, Wang, and Yuan (2020) measured walking speeds with computer vision technique in a severely cold area. They found that walking speed increases in low temperatures and decreases by $0.1 \mathrm{~m} / \mathrm{s}$ on snow.

Information on cycling speeds in winter conditions have been found in non-scientific publications only. There, a slight, unintended speed reduction in snow and low temperatures is reported (Phillips, 2010, Icebike, 2015).

\subsection{Opinions on winter maintenance}

A survey of satisfaction with winter maintenance at pedestrian crossing facilities was conducted by Bach and Böhm (1994). The following points were most frequently criticized:

- In general no or too late clearing or gritting

- No or insufficient treatment of waiting areas at crossing facilities

- No clearing of the curb for changing from the sidewalk to the carriageway at crosswalks

- Particularly high risk of falling on markings and cobblestones

- Snow storage, which prevents pedestrians from crossing the carriageway on a short distance

Similarly, Durth et al. (1995) asked cyclists about their problems with winter road maintenance. Here, the following problem situations were described most frequently:

- Slippery surfaces due to slush

- Slippery surfaces due to freezing slush

- Slippery surfaces caused by frozen snow

- Slippery surfaces due to icy wheel ruts

- Snow piles as obstacles in intersection areas

- Cycle paths covered with additional snow by carriageway maintenance services

- Conflicts with pedestrians due to reduced width in the side space caused by snow deposits

Bergström (2003) conducted a survey of 1,000 employees of two large Swedish companies. In this survey, only $8 \%$ to $15 \%$ of the winter cyclists were satisfied with the winter maintenance on cycle paths. Here, too, the most frequent suggestions for improvement were more frequent and earlier snow removal and de-icing, and the creation of cycle routes that are passable throughout. Overall, the cyclists surveyed gave winter road maintenance a lower rating than car drivers.

Based on observations and interviews, Bergström (2002) describes the problem that cyclists move from the cycle path to the carriageway if the winter road maintenance is inadequate, possibly creating new safety risks. If, on the other hand, cycle paths are cleared earlier than carriageways, there is a risk that the entire cycle path or sidewalk, or parts of it, will be covered with snow again by the winter road service. Therefore, in the optimal case, cycle paths would have to be cleared at the same time as the carriageways. In addition, Bergström (2002) mentions that the application of excessive amounts of gritting materials can again lead to a decrease in skid resistance and that prompt removal after the end of winter weather is important.

A survey among 33 cyclists in Edmonton (Canada) revealed that many cycle paths and carriageways were not cleared and could therefore only be used to a limited extent. Other criticisms included the insufficient clearing width, the lack of a coherent cycling network, and the lack of awareness of cyclists' concerns among other road users (Shirgaokar $\&$ Gillespie, 2016). 
As part of the German ADFC Bicycle Climate Test (ADFC, 2021), every two years more than 100,000 participants give their assessment of various aspects of cycling in their home city in the form of school grades. Cyclists tended to rate winter maintenance as poor, in contrast to other aspects of cycling, and less than $5 \%$ of the cities assessed received a rating on 3 or better for this (where 1 means very good and 6 means very poor). After a slight increase in satisfaction with winter services on cycle paths was registered over the course of the surveys from 2012 to 2016 , the rating fell again in 2018. Larger cities tended to receive worse ratings for winter road maintenance than smaller ones - for example, from 2012 to 2018 Muenster was the only German city with a population of over 100,000 in which winter road maintenance on cycle paths received a rating of 3 or better.

\section{DATA AND METHOD}

In order to analyse the traffic behaviour and indicators for pedestrian and cyclist falls in snowy and icy conditions, their safety-relevant behaviour was recorded by video. The data gathered were compared with those from reference data collected in other weather conditions at the same location (see section 3.1). In parallel to the video observations, on-site surveys of pedestrians were conducted in the same areas (see section 3.2).

The field work took place within a radius of about 100 kilometres around the cities of Aachen and Dresden, Germany, including cities of various sizes as well as winter sports towns. Observations and surveys in snowy/icy conditions were conducted during the three winters between the years 2015 and 2018. Reference data were collected in the remaining seasons in 2016 and 2017. In each city one or several study areas with lengths of 500 to $1000 \mathrm{~m}$ were defined, which were divided in up to four individual camera sections (see Figure 2). The traffic surveys were limited to sidewalks and bicycle paths on major roads, sidewalks on minor roads, crossing facilities and bus stops. An example of the measurement configuration of a survey section is shown in Figure 2. A total of 17 study areas with 43 camera sections were covered. In addition, an online survey was carried out (see section 3.3).

All results referred to in this paper are significant on a level of $5 \%$.

\subsection{Behavior observations}

Behavior of all pedestrians, but only of cyclists on cycle paths and (shared) sidewalks was analyzed. If there was a dedicated cycling facility, also cyclists on the carriageway were analyzed.

Speed of movement was measured only for freely moving road users. Free movement was defined as follows:

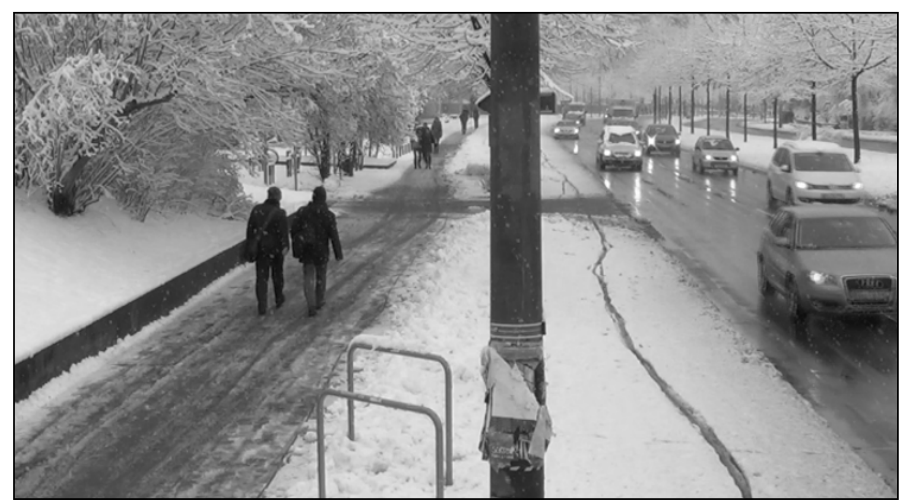

Figure 1. Camera view (example)
- The road user was not hindered by persons walking or driving in front of him or would have been able to overtake them comfortably due to sufficient space.

- The road user was walking or driving alone or was the leader of a group permanently walking or driving next to each other. If no group leader could be identified, any person in the group was selected (This ensured that the speed of the person leading the group was not over-represented by multiple consideration).

For each freely moving road user on the above-mentioned traffic facilities, several characteristics were collected. These include facility usage (side and type of traffic facility used, direction of travel, carriageway crossing), means of transport (pedestrian or cyclist, walker or wheelchair, baby carriage, type of bicycle, bicycle being pushed, in a group, with children, with pets or exercising), distractions (media use, other people, or camera), gender and age group (estimated, more complicated in winter because of warm clothing). Additionally, falls (road user on the ground at least momentarily) and near falls (pedestrian could only avoid a fall by unnatural movements, cyclist could only avoid a fall by putting both feet on the ground) were counted. The safety of movement was rated as follows:

- slightly insecure: pedestrian varied speed or step sequence without stopping, cyclist was riding wavy lines or making obvious corrective steering movements without setting foot on the ground,

- very insecure: pedestrian had to stop at least once, cyclist had to put a foot on the ground at least once,

If the road users did not stop and haven't been distracted, their speed of movement was calculated from the time required to travel a defined distance.

In total 190 hours of video were analyzed. During this time, the speeds of 7,058 pedestrians and 4,502 cyclists were measured and the other behavioral and personal characteristics were collected from a total of 9,299 pedestrians and over 4,668 bicyclists.

\subsection{On-site surveys}

During the time of the video recordings and in the same sections, on-site surveys were conducted in both snowy/icy and other conditions. The participants of the on-site surveys during snowy/icy conditions were (besides other things) asked about the circumstances of their respective last falls in both snowy and icy conditions. Topics included facility used and surface conditions during the falls as well as causes for the falls. These questions about the respective last falls were asked identically in the online survey.

In total 1,581 pedestrians and 505 cyclists participated in the on-site surveys. While female and male respondents participated to a similar extent, persons between the ages

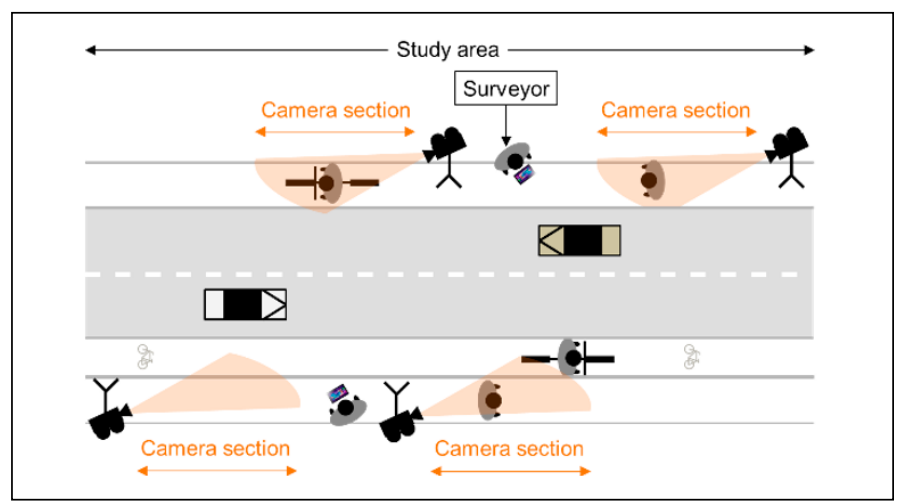

Figure 2. Setup for field work 
of twenty and thirty are overrepresented, and the group of forty to sixty years old, which is prominent in the German population as a whole, is underrepresented. Children under the age of 14 have not been surveyed.

\subsection{Online surveys}

Compared to the on-site surveys, some additional questions about the respondents respective last falls, such as types of bicycles used and shoes worn, were asked in the online survey. Furthermore, questions about respondent's experiences and opinions in relation to winter maintenance were asked. Participants were also asked to state the frequencies of usage of different modes of transport in winter time. Respondents who cycle at least once per week also during winter were defined as active winter cyclists.

At the end, respondents were asked to specify personal information (gender, age, postal code). As in the on-site surveys, participants in the online survey also had the opportunity to explain general problems or suggestions for improvement at the end of the questionnaire.

Participation in the online survey was possible from January to early February 2017. The link to access the online survey was initially distributed to all approximately 8,000 employees and 2,000 student assistants of the TU Dresden via internal mailing list on January $10^{\text {th }}, 2017$. Additionally, the TU Dresden called for participation on January $30^{\text {th }}$, 2017 with its Twitter account (over 7,000 subscribers). On February $1^{\text {st }}, 2017$, the link to the online survey was distributed among the approximately 400 employees of the German Federal Highway Research Institute in Bergisch Gladbach. In addition, the link was apparently shared by some participants.

In total, the link to the online survey was accessed by over 7,000 people, of whom 3,338 completed the questionnaire in its entirety. Almost all participants were between 18 and 65 years of age. Among them, men (57\%) and people between 20 and 40 years of age were overrepresented compared to the total German population. A total of 3,105 participants entered the first two digits of the postal code of their place of residence. Of these, around two thirds were based in region 01 (cities of Dresden, Riesa, Meissen, Bischofswerda) and just over three percent in region 51 (cities of Cologne, Leverkusen, Bergisch Gladbach, Gummersbach).

\section{RESULTS}

\subsection{Correlates of falls in snowy/ice conditions}

\subsubsection{Fall causation}

The participants in our online and on-site surveys identified a variety of causes for their falls as pedestrians in other weather conditions. For falls in snowy/icy conditions, surface conditions were predominantly reported as causal (78\%). In contrast, wet conditions were listed as the cause of $16 \%$ and grit remnants as the cause for $4 \%$ of the pedestrian falls in other weather conditions (see Figure 3). Correlation analysis with other variables of the survey showed, that pedestrians aged 15 to 24 more frequently reported swerving obstacles or other road users as a cause for their fall in snow/ice than pedestrians aged 45 to 64 (5\% vs. $1 \%$ ).

Snow/icy surfaces themselves were also most frequently cited as the cause of cyclist falls in snowy/icy conditions. although this cause was reported less frequently by respondents aged 45 to 64 than by younger respondents. Furthermore, at about two-thirds, this proportion is lower than that for pedestrian falls. For cyclist falls in other weather conditions, the respondents also identified a variety of causes. Wetness and grit remnants as causes for cyclist falls in non-critical weather show quite similar shares compared to pedestrian falls (19\% and $3 \%$ respectively, see Figure 4$)$.
For both pedestrian and cyclist falls, we did not notice significant differences in fall causation in snowy/icy conditions between women and men or between frequent and infrequent winter cyclists.

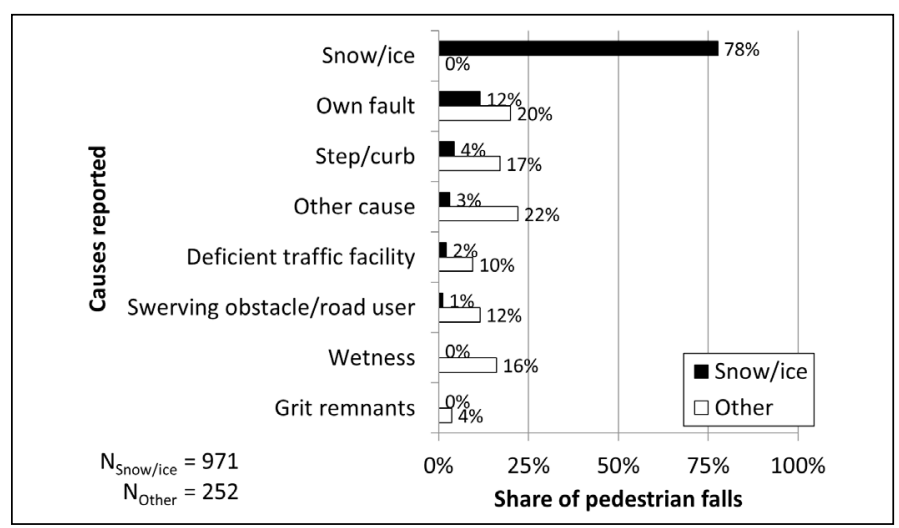

Figure 3. Reported cause of respective last pedestrian fall in snowy/icy and other conditions

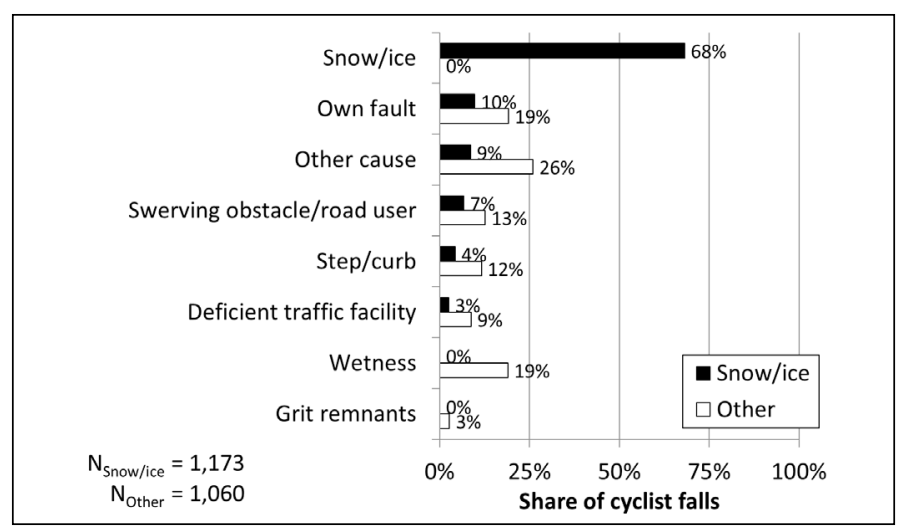

Figure 4. Reported cause of respective last cyclist fall in snowy/ icy and other conditions

\subsubsection{Equipment when falling in snowy/icy conditions} During the reported pedestrian falls in snowy/icy conditions, $1 \%$ of the respondents used studs, while most of them wore shoes with a weak treat pattern (62\%), followed by a third which has worn shoes with a strong treat pattern. Among women, shoes with a strong treat pattern were worn more frequently while falling than among men $(38 \%$ and $30 \%$ respectively, see Figure 5).

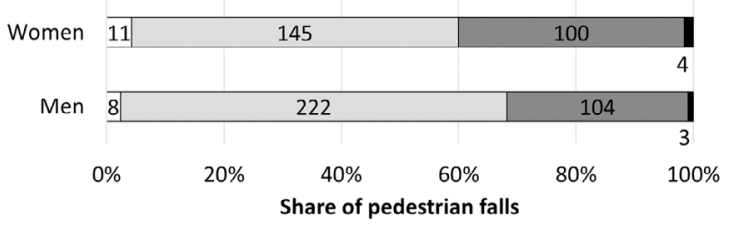

$\square$ No treat pattern $\square$ Weak treat pattern $\square$ Strong treat pattern $\square$ Studs

Figure 5. Shoes or equipment worn during reported pedestrian falls

Overall $6 \%$ of the reported cyclist falls in snowy/icy conditions happened using spiked tires. Frequently occurring bike types in cyclist falls were trekking bikes (42\%), classic bikes (32\%) and mountain bikes (19\%).

During their respective last cyclist falls in snowy/icy conditions, compared to women a higher share of men fell using road bikes ( $0 \%$ and $2 \%$ respectively) and mountain bikes (15\% and $21 \%$ respectively) and a lower share of men fell using trekking bikes ( $21 \%$ and $15 \%$ respectively, see Figure 6). 


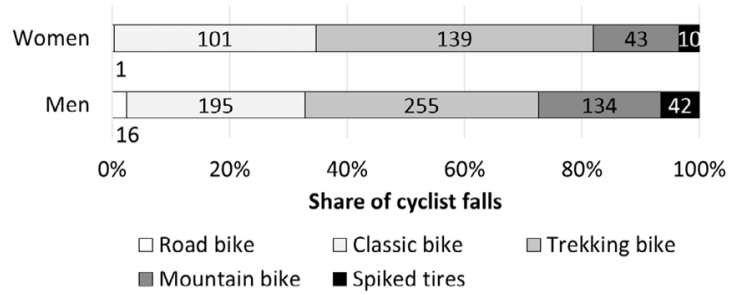

Figure 6. Bike type or equipment used during reported cyclist falls

A higher proportion of active winter cyclists was using spiked tires during their falls in snowy/icy conditions than inactive winter cyclists ( $6 \%$ and $1 \%$ respectively). Apart from that, no significant difference in distributions of bicycle types have been found between this two groups.

This question was asked to a sub sample of participants in the online survey.

\subsubsection{Surface conditions when falling}

Nearly two-thirds of the reported pedestrian and bicyclist falls in winter conditions occurred on ice (59\% and $60 \%$ respectively). In both pedestrian and bicyclist falls, fresh snow was less common than packed snow, with fresh snow being more common in bicycle falls than in pedestrian falls (see Figure 7).

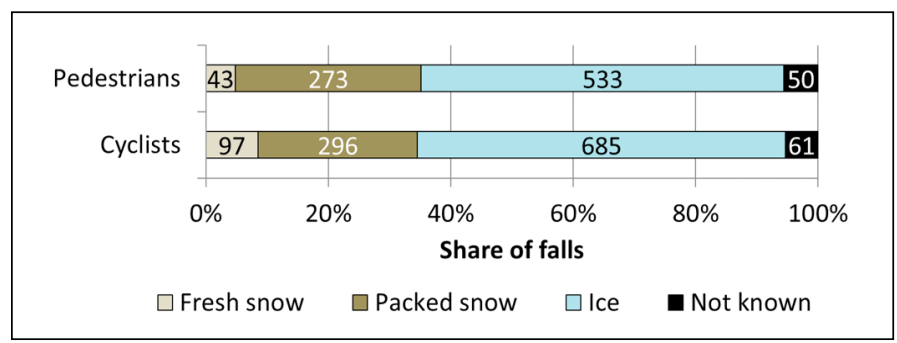

Figure 7. Reported cause of respective last pedestrian fall in snowy/icy and other conditions

Only a small proportion of reported falls were remembered as having a well cleared surface. About their pedestrian falls on packed snow, $57 \%$ of respondents reported poor clearing and $34 \%$ reported no clearing at all. Of the reported cyclist falls on packed snow, $46 \%$ occurred on poorly cleared surfaces and $49 \%$ occurred on non-cleared surfaces (see Figure 8 ).

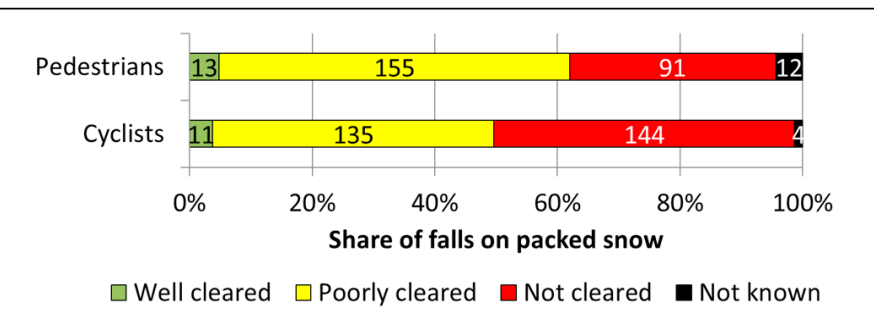

Figure 8. Reported cause of respective last pedestrian fall in snowy/icy and other conditions

For the majority of all reported falls, respondents indicated that they had not detected any grit applied to the surface. This proportion is higher for all cyclist falls (66\%) than for all pedestrian falls (55\%), and higher for falls on icy surfaces (cyclist falls: $72 \%$, pedestrian falls: $60 \%$ ) than for those on packed snow (cyclist falls: $59 \%$, pedestrian falls: $49 \%$ ). Conversely, only a few of the reported falls occurred despite maintained surfaces. Gritting was reported more frequently than de-icing, especially in the case of pedestrian falls and falls on packed snow (see Figure 9). Male cyclists more frequently fell on untreated surfaces (no salt or grit, $87 \%$ of reported falls) and less frequently fell on gritted surfaces (8\%) than female cyclists ( $80 \%$ and $13 \%$ respectively). This also accounts for age - the older the cyclists, more frequently they fell on untreated surfaces and the less frequently they fell on gritted surfaces. For all of the sub groups, the share of falls on de-iced surfaces was below $10 \%$ and did not differ significantly. It should be noted that for about one in five reported falls, respondents could not recall the scattering condition, regardless of the circumstances.

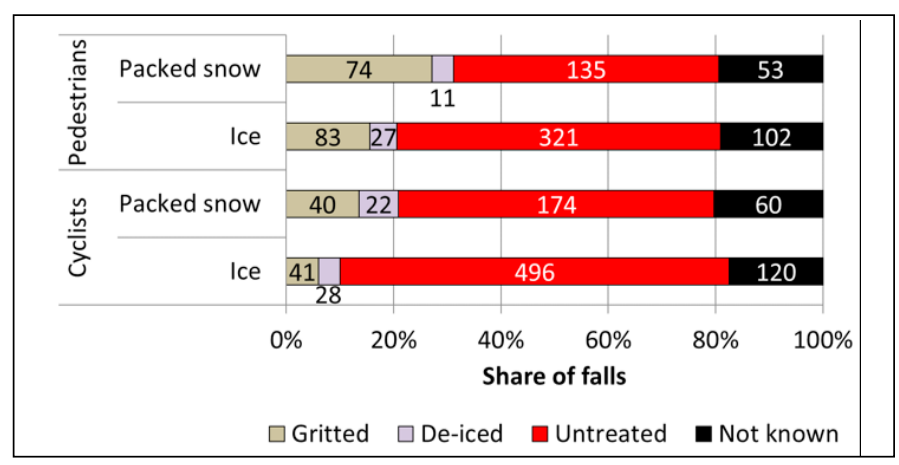

Figure 9. Reported cause of respective last cyclist fall in snowy/ icy and other conditions

No significant differences between frequent and infrequent winter cyclists was found regarding the surface and clearance conditions, on which the falls had happened.

\subsubsection{Level of experience among persons falling}

In the reported pedestrian falls during snowy/icy conditions, the share of winter experienced pedestrians did not significantly differ from that in other surface conditions. Otherwise, the proportion of active and thus experienced winter cyclists (78\%) was higher in cyclist falls in snowy/ icy conditions than those in other surface conditions (63\%, see Figure 10).

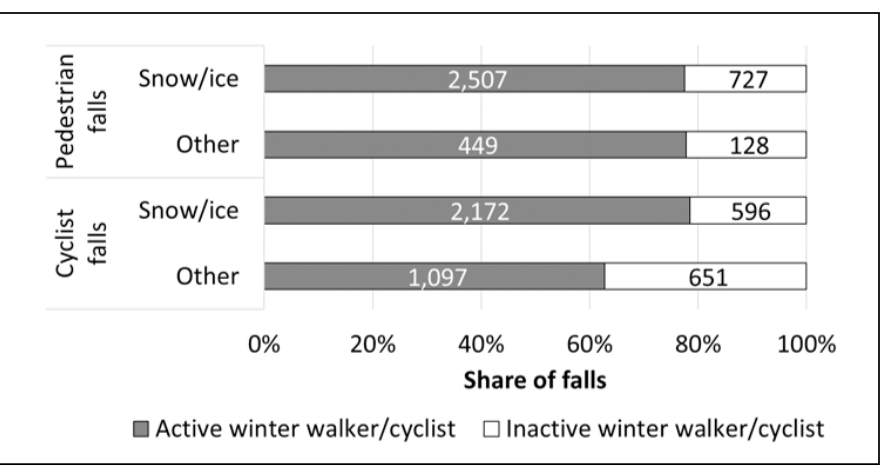

Figure 10. Reported falls by walking and cycling experience of pedestrians and cyclists

\subsection{Behavior in snowy conditions}

\subsubsection{Bicycle type usage}

In snow and snow slush we observed increases in the shares of mountain bikes and trekking bikes as well as decreases in the shares of classic bikes and road bikes compared to dry or wet surface conditions. In snow slush, we also observed an increase in the share of mountain bikes and a decrease in the share of classic bikes compared to dry surface conditions. Compared to wet conditions, in snow slush we only observed an increase in the share of mountain bikes (see Figure 11).

For persons aged 45 to 64 we observed the highest share of trekking bikes and the lowest share of mountain bikes in all conditions. In this age group, in snowy conditions we also found an increase in the share of trekking bikes and a decrease in the share of classic bikes compared to dry surface 


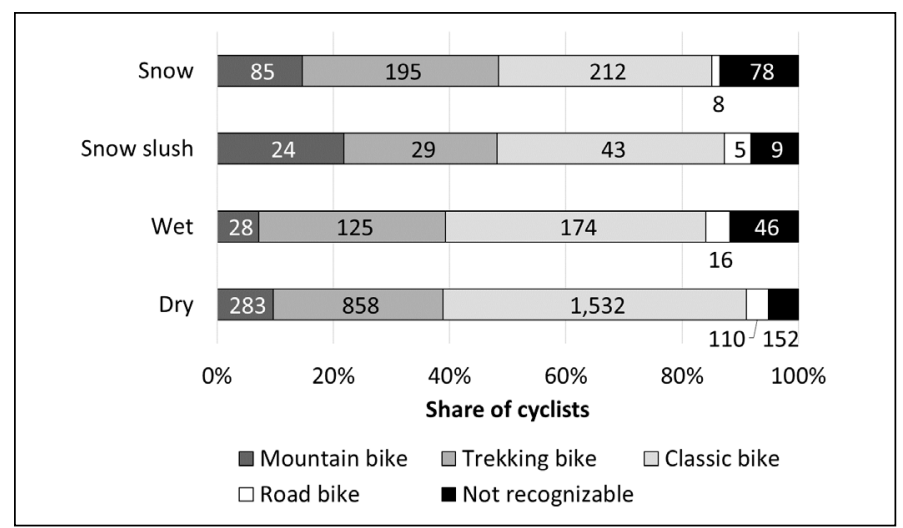

Figure 11. Bicycle type usage in different surface conditions

conditions, but no differences in bike type usage between snowy and wet surface conditions. For people aged 25 to 44 , in snowy conditions we observed an increase in the share of mountain bikes compared to both dry and wet conditions and decreases in the shares of classic bikes and road bikes compared to dry conditions.

However, in the age group of 15 to 24 aged cyclists we found no differences in bicycle type usage in snowy conditions compared to dry conditions and for persons older than 65 or younger than 15 the sample sizes were too low. Among female cyclists, besides an overall higher share of classic bikes and a lower share of mountain bikes, we found no significant changes in bicycle usage in different surface conditions. In snow and rain, it was harder to determine features from the video recordings, which resulted in a higher share of not recognizable bicycle types in the corresponding surface conditions. We also conducted observations when there were snow remnants on the surface, but did not collect sufficient sample size either.

\subsubsection{Cyclists' facility usage}

We observed significant differences in cyclists' small-scale route choice behavior in street sections with separated paths for cyclists and pedestrians, of which non have been maintained during our winter observations. Whilst in dry surface conditions during the reference observations, over $80 \%$ of the cyclists in these sections used the dedicated and compulsory cycle path, this share dropped to $7 \%$ during snow slush and close to zero in snowy conditions. Instead, most of the cyclists cycled on the sidewalk even in conditions without winter service in these areas. Only a small proportion of persons was observed cycling on the carriageway in surface conditions of snow (9\%) or snow slush (15\%, see Figure 12$)$. Similar shifts from using the cycle path in dry conditions to cycling on the sidewalk in snowy conditions were observed among all age groups between 15 and 64 .

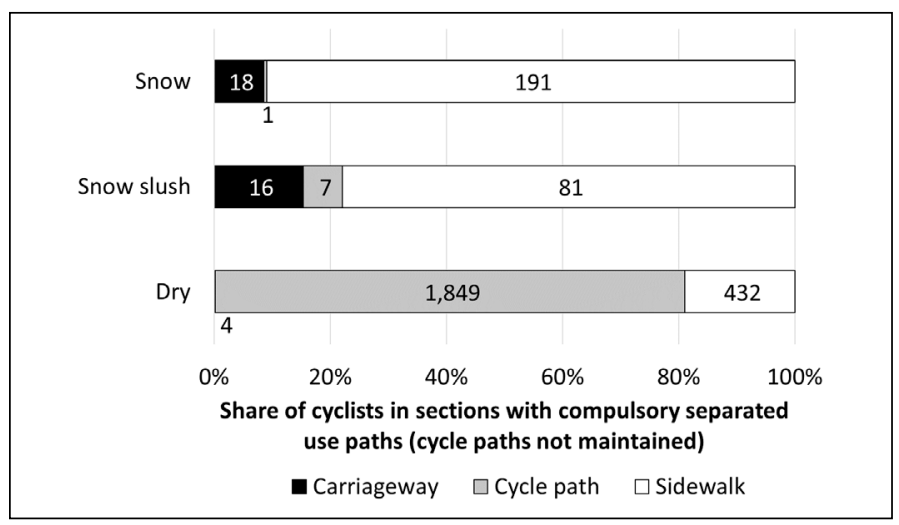

Figure 12. Cyclist's facility type usage in street sections with compulsory separated use paths during different surface conditions

\subsubsection{Speed of movement}

While explaining the following cycling and walking speeds, we refer to the median values of the measured speed distributions.

Walking speeds did not differ significantly between uphill and flat sections and are all at $1.4 \mathrm{~m} / \mathrm{sec}$. In downhill sections, walking speeds in snowy conditions $(1.5 \mathrm{~m} / \mathrm{sec})$ were slightly but still significantly lower than those in dry conditions $(1.6 \mathrm{~m} / \mathrm{sec})$. Both are significantly higher than speeds in uphill and flat sections. Overall the differences in walking speeds did not reach the level of differences in cycling speeds (see Figure 13).

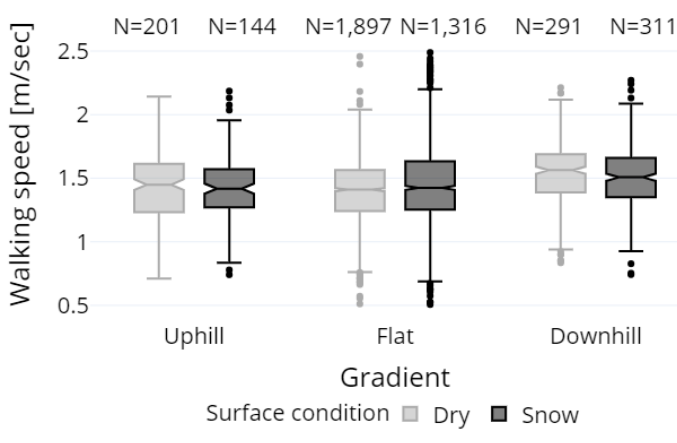

Figure 13. Walking speeds in different gradients and surface conditions

Cycling speeds on uphill sidewalks did not significantly differ between dry and snowy conditions (median values of 3.3 and $3.4 \mathrm{~m} / \mathrm{sec}$ respectively). Also in the flat, no significant difference in cycling speeds could be measured on sidewalks for these to surface conditions (both $4.7 \mathrm{~m} / \mathrm{sec}$ ). Regardless of the surface conditions on flat sidewalks cyclists rode about a third faster than on uphill sidewalks. In dry conditions, with a median value of $7.0 \mathrm{~m} / \mathrm{sec}$ even higher speeds were measured on downhill sidewalks than on flat sidewalks, which represents an increase of almost one half. This is in contrast to a reduction in the speed of cyclists on downhill sidewalks in snowy conditions to a median value of $4.2 \mathrm{~m} / \mathrm{sec}$ compared with flat sidewalks (- $11 \%)$. Viewed the other way around, this leads to 1.7 times slower cycling speeds on downhill sidewalks in snowy conditions compared to dry conditions (see Figure 14).

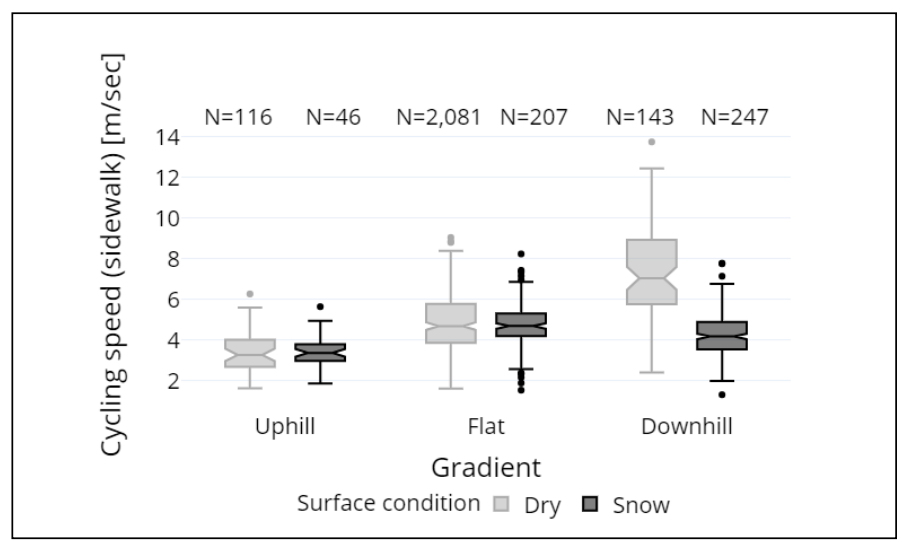

Figure 14. Cycling speeds on the sidewalk in different gradients and surface conditions

Sufficient sample sizes for comparing different types of cycling facilities are only available for sidewalks in the flat and for both surface conditions of drought and snow remnants. In snow remnants we found significant reductions in cycling speeds on cycle paths (5.0 to $4.6 \mathrm{~m} / \mathrm{sec}$ ) and also on sidewalks (5.8 to $3.7 \mathrm{~m} / \mathrm{sec}$, see Figure 15 ). 


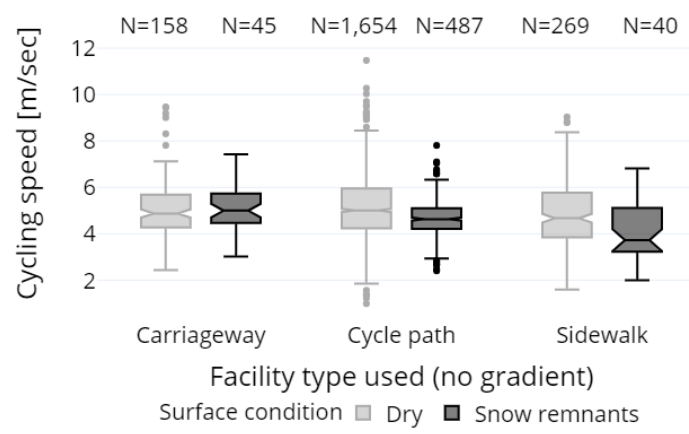

Figure 15. Cycling speeds in the flat on different types of facility and in different surface conditions

\subsubsection{Safety rating of movement}

We rated the safety of movement of the cyclists and pedestrians in the study areas by the characteristics described in chapter 3.1. In conditions of drought, wetness and snow remnants, more than $99 \%$ of pedestrian's and cyclist's movements observed in the video recordings were rated as secure. This also accounts for snow slush, when the sidewalk had been maintained. While during conditions of both not cleared snow slush and cleared snow $6 \%$ of pedestrian's movements were rated as at least slightly insecure, this proportion is $11 \%$ in conditions of not cleared snow (see Figure 16).

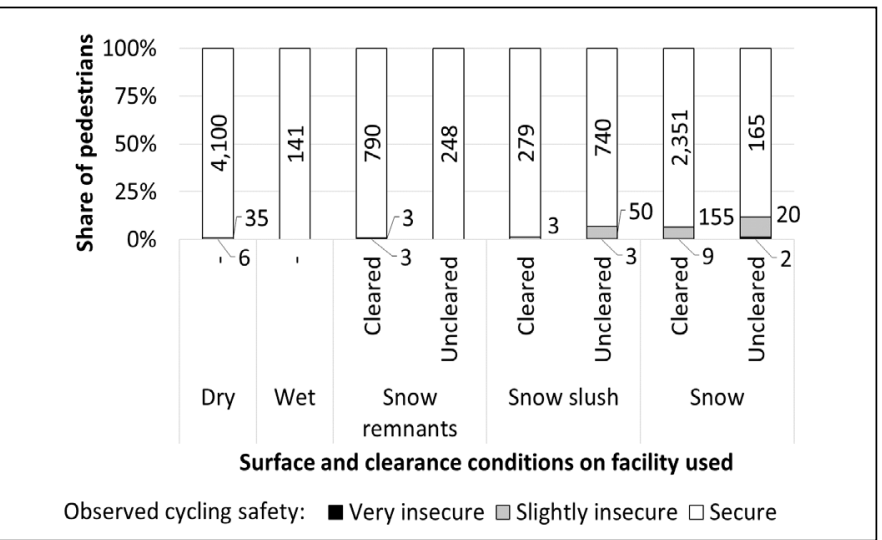

Figure 16. Rating of walking safety in different surface and clearance conditions

These were also the conditions in which for a proportion of cyclists the safety of movement was rated as at least insecure, which exceeds that of pedestrians. The share of at least slightly insecure moving rated cyclists is higher on cleared than on not cleared snow ( $23 \%$ and $17 \%$ respectively), but this difference is not statistically significant. During not cleared conditions of snow slush an even higher share ${ }^{1}$ of cyclists has been rated as moving at least slightly unsecure (28\%), including the maximum number of cyclists classified as moving very insecure among all surface conditions (6, see Figure 17).

Sample sizes and rating distributions only allowed the analysis of further aspects for conditions of cleared snow: There were higher shares of women than men rated as walking ( $8 \%$ vs. $5 \%$ ) and cycling ( $27 \%$ vs. $14 \%$ ) at least slightly insecure. Within the age range of 15 to 64 the ratings of cycling (17 to $21 \%$ ) and walking safety ( 3 to $5 \%$ ) showed no significant differences, while for a significantly higher share (17\%) of the elderly (65+) their walking safety was rated as at least slightly insecure on cleared snow.

1 The share of cyclist's movements on not cleared snow slush rated as at least slightly insecure is significantly higher than that on cleared snow, but not significantly higher than that on not cleared snow.

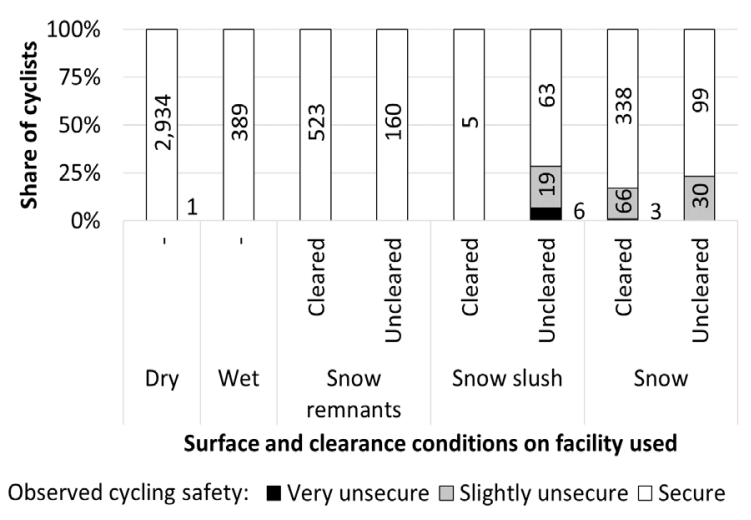

Figure 17. Rating of cycling safety in different surface and clearance conditions

\subsection{Opinions on winter maintenance}

The participants of the online survey were asked to rate the winter maintenance on different types of traffic facilities at their place of residence. Three quarters of the respondents rated the cycle paths as "poor" or "fairly poor", compared with positive ratings from $12 \%$. Winter maintenance on sidewalks received more good ratings (57 \%) than poor ratings (39\%). Crossing facilities and their waiting areas were rated slightly worse than sidewalks, although the proportion of positive ratings slightly exceeds here as well. Winter services were rated best at bus stops with $72 \%$ good and rather good assessments (see Figure 18).

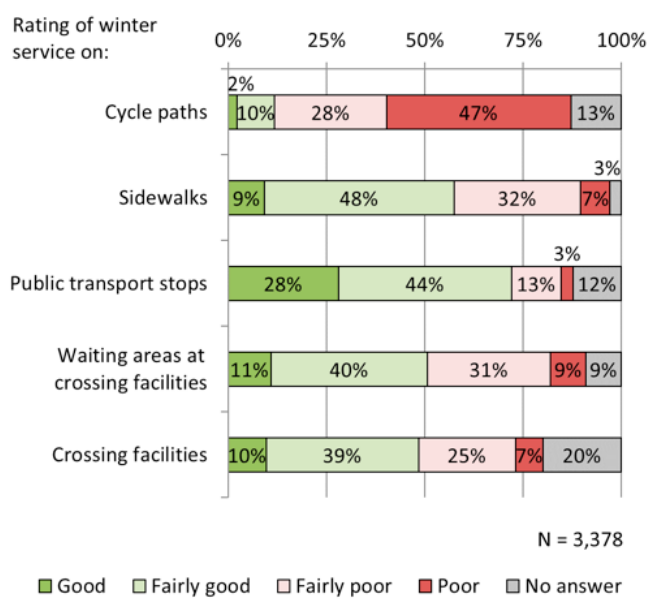

Figure 18. Evaluation of the winter service at respondents' place of residence according to the type of traffic facility

In addition, the respondents were given some theses about winter road maintenance, which they were asked to assess in relation to their place of residence. These statements were randomly displayed to the participants either in relation to sidewalks or in relation to bicycle paths. Only a minority of respondents agreed or rather agreed that on bicycle paths only a few sections are not maintained at all (15\%), action is taken promptly after the precipitation event (6\%), and sections already maintained are treated again if necessary (11\%). For sidewalks, $29 \%$ to $37 \%$ of the participants at least rather agreed with these statements. The push-back of snow from the street onto sidewalks by snowplow vehicles was named as a problem by $37 \%$ of the respondents for sidewalks and $57 \%$ of the respondents for cycle paths (see Figure 19). It should be noted here that the respondents may also have associated cycle lanes or protective lanes with the term cycle paths.

At the end of the online survey, the participants were able to describe in their own words the aspect of winter maintenance that was most important to them. A total of 1,700 free com- 


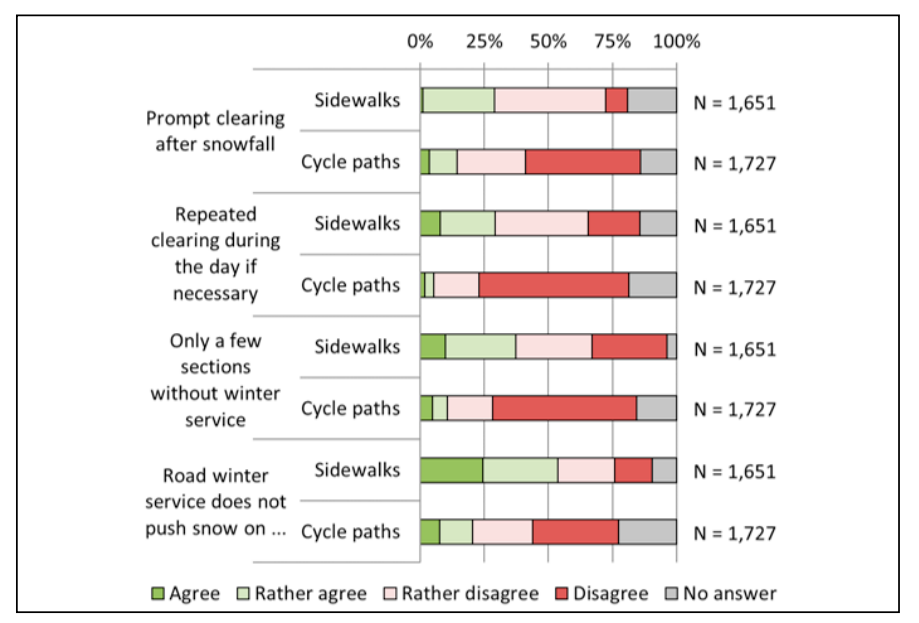

Figure 19. Evaluation of proposed statements on winter maintenance in relation to respondents' place of residence.

ments from respondents were systematically analyzed and classified into more than 100 categories and subcategories. The following comments were given most frequently:

- Cycle paths are not treated, not treated continuously, or not treated adequately (219 mentions)

- Sidewalks and bike lanes (or driveways) are covered with snow by winter road maintenance (131)

- In general, there is a positive trend in winter maintenance on sidewalks and bike paths (123)

- Winter service on sidewalks and bike paths in the secondary network is in need of improvement (102)

- After snowfall or occurrence of icy conditions, winter service is not performed in proper time (91)

\section{DISCUSSION AND CONCLUSIONS}

Confirming the findings of Furian et al. (2011) and Nyberg et al. (1996), respondents to our surveys reported snow/ ice as the cause for four out of five pedestrian falls and two out of three cyclist falls in winter conditions. By contrast, wetness was cited as the cause in only under $20 \%$ of falls in other weather. Can the conclusion be drawn that snow/ ice causes a higher risk of falls for pedestrians and cyclists than wet conditions? In the years 2012 to 2016, precipitation of more than 1 liter per square meter was recorded on approximately 30 \% of days in Dresden, Germany (DWD 2018). Since on these days not necessarily the whole 24 hours are characterized by wet surfaces, a conclusive comparison of wet and snow/icy surfaces is not possible based on the survey methodology.

Although surfaces in Central Europe are less often covered by ice than by snow, the proportion of reported falls in icy conditions is significantly higher than in snowy conditions. This is in line with the findings of Bach and Böhm (1994), Ruotsalainen et al. (2004) and Amiri and Sadeghpour (2014) and can be related to three reasons:

- The more difficult prediction time and place of icy conditions compared to snowfall events,

- the poor visual detectability of icy surface segments, and

- the reduced effect of gritting materials on ice compared to snow (FGSV, 2010).

Before periods of ice, the preventive usage of de-icing solutions (brine) or the curative usage of sand should be considered both for winter maintenance done by the municipality and also by residents, if they are capable for reducing the risk of falls and ecological standards for such de-icing materials as well as guidance on how to use these materials can be developed. Further, more accurate prediction models, ice sensors on walking and cycling facilities and warning the public via mobile apps could help mitigate this problem. Also new types of pavement materials could decrease the formation of ice, as Wallqvist et al. (2017) propose.

Overall, relatively few falls were reported on well-maintained surfaces. This may mean that quite a few falls are prevented by good winter maintenance, or, if there are hardly any well-maintained surfaces overall, it may just mean the opposite. It is thus a question of exposure of pedestrians and cyclists to these maintenance conditions.

Reported cyclist falls frequently happened on non-cleared and non-treated surfaces, which is in line with our findings from the same online survey, that the cycle paths of the municipalities are not considered to be adequately maintained in terms of winter services. Even though the share of cleared surfaces was higher for pedestrian falls, only a few were reported as "well cleared". This on the other hand, contrasts with the other results of the same online survey, where winter service was rated as mostly good by more than half of the respondents. Also the observation of walking and cycling safety in snowy conditions showed for both pedestrians and cyclists only a slight increase of insecure movements, when surfaces have been left un-cleared. Elvik (2000) and Möller et al. (2013) faced the same issues and concluded, that the higher the perceived risk, the more careless road users move. Following this theory, occasional segments of poor maintenance in an apart from that well-maintained network can lead to a high risk of falls. As this is primarily an issue when residents are responsible for winter maintenance on sidewalks, in the city of Helsinki (Finland), sidewalk maintenance has been made a municipal responsibility (Helsingin kaupunki, 2020). Since winter conditions are less common in Central Europe and it is too expensive to keep staff and devices on standby all year round, this could be a solution at least for some problematic downtown areas.

Although gritting materials are considered to be almost ineffective in icy conditions (FGSV, 2010), we have been reported only a few falls on grit in icy conditions (and also among all cyclist winter falls). This can in fact be attributed to small exposure, as de-icing materials are used more frequently than gritting materials both on cycle paths and in icy conditions. Even though we observed during the video observations that grit remains on the surface for several weeks after snowfall events, grit was not frequently cited as a cause of pedestrian or cyclist falls.

During the reported falls in icy/snowy conditions, like Bach and Böhm already found in 1994, less than half of the pedestrians wore adequate shoes and nearly none of them used studs. It would be interesting to compare this with wearing rates among all pedestrians. The proportion of bicycle types used in reported falls in ice and snow does not appear to differ from that in traffic observations among all bicyclists in these conditions.

The same share of active winter walkers was noticed in reported falls in both snowy/icy and other conditions, although active winter walkers are exposed more often to winter conditions and potential falls. This resembles the results of Gao and Abeysekera (2004), that walking experience can have a positive effect on walking safety in snowy/icy conditions. As we noticed a higher share of active winter cyclists among falls in snowy/icy than in other conditions, no such conclusion can be drawn for cycling experience.

None of the cycle paths we observed have been maintained in snowy conditions. As a consequence, nearly all of the cyclists switched to using the sidewalks and not the carriageway (even if in Germany they are obliged by law to use the carriageway in such cases). This contrasts the findings Durth et al. (1995) and Bergström (2002), who observed cyclists switching to the sidewalk only sometimes. Bergström (2002) also notes, that being forced to cycle on the carriageway could 
cause other traffic safety issues. Given that, a legal option for cyclists to use the sidewalk in icy/snowy conditions when the cycle paths are usable should be discussed particularly for carriageways with high volumes of Motorised Traffic.

We measured quite similar pedestrian speeds (median value of $1,4 \mathrm{~m} / \mathrm{sec}$ ) researchers in the other studies mentioned above. Like Liang et al. (2020) we found slight differences in pedestrian speeds between snowy and dry conditions, but in our sample this only applies to downhill sections. For both snowy and dry conditions, we measured higher pedestrian speeds in downhill sections than in the respective conditions in the flat or uphill, which confirms the results of Weidmann (1992).

We hardly found any scientific literature on cycling speeds in snowy conditions. However, on sidewalks we measured higher speeds in the flat than uphill in both snowy and dry conditions, which did not differ significantly by surface condition. In dry conditions, we measured considerably higher cycling speeds in downhill sections compared to flat sections. By contrast, in snowy conditions we registered lower speeds than in the flat under the same surface conditions. Not on flat carriageways but on flat cycle paths and sidewalks, we found reductions of cycling speeds when there were snow remnants (compared to dry conditions).

Winter maintenance on sidewalks received more good than bad ratings. As also stated by Bach and Böhm (1994), delayed maintenance after snowfall events is a problem for at least half of the respondents to our online survey and the same accounts for repeated clearing during the day. Similar to the ADFC German Bicycle Climate Test (2021), Shirgaokar and Gillespie (2016) and Bergström and Magnusson (2003), cycling facilities received very poor ratings in terms of winter maintenance. Similar to Bergström (2002), many respondents criticized a lack of seamlessly maintained cycling facilities. First steps towards such a network have been made in Austria and Finland, which in their national guidelines define a prioritized winter road service for specified cycling routes, depending on their function and traffic load. For example, in some cities in Northern Europe, winter maintenance on pedestrian and cyclist facilities has even been prioritized over carriageways to increase safety and promote these active modes of transport. In the Netherlands, cycle paths have priority over sidewalks, so unlike our results, one would not expect cyclists to use sidewalks instead of designated cycling facilities (but perhaps vice versa). But also controlling and monitoring of winter maintenance by both administrations and by crowdsourced approaches could help to better level the quality of maintenance for sidewalks and cycle paths.

The conclusions drawn from the data analyzed in this study concern German conditions, and their transferability to other countries is limited. This is mainly due to the aforementioned differences in winter maintenance. Also the sample for the online survey was mainly recruited in the region of Dresden in the eastern part of Germany. This might cause a bias if winter conditions substantially differ between eastern and western Germany.

Because the frequency and length of pedestrian and cyclist trips may differ in snow/ice and other conditions, future studies should also consider the exposure-related fall risk of pedestrians and bicyclists. Furthermore, it can be expected that risk perception has a major influence on walking and cycling behavior. For example, unexpected poorly maintained sections could lead to deviations between actual and perceived risk and be one cause for particularly high numbers of falls in certain areas. There might be also a relation to the differences in actual risks by age and gender as mentioned by Schepers et al. (2017). This could be another interesting avenue for future research. In addition, it would be interesting to compare the wearing rates of spikes or the fitting rates of bicycle spikes in fallen versus all pedestrians and cyclists.

\section{Author contribution}

Martin Bärwolff: Conceptualization, Methodology, Investigation, Data collection, Data Curation, Formal analysis, Visualization, Writing - Original Draft. Angelika Reinartz: Investigation, Data collection, Data curation. Regine Gerike: Conceptualization, Resources, Project administration, Supervision, Writing - Review and Editing.

The work is based on data and methods collected and applied as part of a research project (Bärwolff et al., 2019) conducted primarily by the contributing authors.

We like to thank our student workers for supporting data collection and our colleagues for professional advice.

\section{Funding}

The study leading to this article was funded by the German Federal Highway Research Institute.

\section{REFERENCES}

Abeysekera, J., \& Gao, C. (2001). The identification of factors in the systematic evaluation of slip prevention on icy surfaces. International Journal of Industrial Ergonomics, 28(5), 303-313. https://doi.org/10.1016/S0169-8141(01)00027-0

ADFC (2021). ADFC-Fahrradklima-Test: Zufriedenheits-Index der Radfahrenden in Deutschland. Retrieved from https://fahrradklima-test.adfc.de/

Alrutz, D., Bohle, W., Müller, H., \& Prahlow, H. (2009). Unfallrisiko und Regelakzeptanz von Fahrradfahrern: Accident risk and rule acceptance of cyclists. Bergisch Gladbach, Germany: Research report of the German Federal Highway Research Institute.

Amiri, M., \& Sadeghpour, F. (2014). Cycling characteristics in cities with cold weather. Sustainable Cities and Society, 14, 397-403. https://doi.org/10.1016/j.scs.2013.11.009

Bach, V., \& Böhm, P. M. (1994). Umfang und Durchführung des Winterdienstes auf Fußgänger-Querungen. Forschung Straßenbau Und Straßenverkehrstechnik. (706).

Bärwolff, M., Schmotz, M., Gerike, R., Baier, R., Reinartz, A., \& Cekin, O. C. (2019). Bewertung des Sturzrisikos und des Verhaltens von Fußgängern und Radfahrern bei winterlichen Bedingungen. Retrieved from https://bast.opus.hbz-nrw.de/ frontdoor/index/index/docId/2339

Bergström, A. (2002). Winter maintenance and cycleways (PhD Thesis). Royal Institute of Technology, Stockholm. Retrieved from http://www.diva-portal.org/smash/record. jsf?pid=diva2:9136

Bergström, A. (2003). More Effective Winter Maintenance Method for Cycleways. Transportation Research Record: Journal of the Transportation Research Board, 1824, 115-122. https://doi. org/10.3141/1824-13

Bergström, A., \& Magnusson, R. (2003). Potential of transferring car trips to bicycle during winter. Transportation Research Part a: Policy and Practice, 37(8), 649-666. https://doi.org/10.1016/ $\underline{\text { S0965-8564(03)00012-0 }}$

Bonander, C., \& Holmberg, R. (2019). Estimating the effects of a studded footwear subsidy program on pedestrian falls among older adults in Gothenburg, Sweden. Accident; Analysis and Prevention, 132, 105282. https://doi.org/10.1016/j. aap.2019.105282

Durth, W., Hiersche, E.-U., \& Lamm, R. (1995). Winterdienst auf Radwegen: Winter service on cycle paths. Karslruhe: Karlsruher Institut für Technologie - Institut für Straßen- und Eisenbahnwesen (ISE).

Elvik, R. (2000). Konsekvensanalyser av bedre vintervedlikehold for gående og syklende: Via Nordica.

FGSV (2010). Merkblatt für den Winterdienst auf Straßen (FGSV R2 - Regelwerke No. FGSV 416). Köln. 
Fossum, M., \& Ryeng, E. (2019). Pedestrians' route choice during winter conditions. ICTCT. 32nd ICTCT Conference, Warsaw.

Furian, G., Kühnelt-Leddhin, A., \& Bauer, R. (2011). Unfallrisiko auf Fußwegen in Österreich. Wien: Forschungsarbeiten des österreichischen Verkehrssicherheitsfonds.

Gao, C., \& Abeysekera, J. (2004). A systems perspective of slip and fall accidents on icy and snowy surfaces. Ergonomics, 47(5), 573-598. https://doi.org/10.1080/0014013041008165 $\underline{8718}$

Gard, G., \& Lundborg, G. (2000). Pedestrians on slippery surfaces during winter--methods to describe the problems and practical tests of anti-skid devices. Accident; Analysis and Prevention, 32(3). https://doi.org/10.1016/s00014575(99)00070-6

Gupta, A., Li, Y., \& Fernie, G. (2008). Effects Of Temperature And Time Of Day On Pedestrian Walking Speed. Proceedings of ICADI 2008: International Conference on Aging, Disability and Independence.

Helsingin kaupunki (2020). Winter street maintenance. Retrieved from https://www.hel.fi/helsinki/en/maps-and-transport/ streets-traffic/maintenance/winter-street-maintenance/winterstreet-maintenance

Hsu, J., Shaw, R., Novak, A., Li, Y., Ormerod, M., Newton, R., . . Fernie, G. (2016). Slip resistance of winter footwear on snow and ice measured using maximum achievable incline. Ergonomics, 59(5), 717-728. https://doi.org/10.1080/00140139 .2015 .1084051

Icebike (2015). This is Why You Are Cycling Slower in the Winter. Retrieved from http://www.icebike.org/this-is-why-you-arecycling-slower-in-the-winter/

Koszowski, C., Gerike, R., Hubrich, S., Götschi, T., Pohle, M., \& Wittwer, R. (2019). Active Mobility: Bringing Together Transport Planning, Urban Planning, and Public Health. In B. Müller \& G. Meyer (Eds.), Lecture Notes in Mobility. Towards User-Centric Transport in Europe (Vol. 26, pp. 149-171). Cham: Springer International Publishing. https://doi. org/10.1007/978-3-319-99756-8_11

Larsson, A., Berggård, G., Rosander, P., \& Gard, G. (2019). Gait Speed with Anti-Slip Devices on Icy Pedestrian Crossings Relate to Perceived Fall-Risk and Balance. International Journal of Environmental Research and Public Health, 16(14). https://doi. org/10.3390/ijerph16142451

Li, Y., \& Fernie, G. (2010). Pedestrian behavior and safety on a two-stage crossing with a center refuge island and the effect of winter weather on pedestrian compliance rate. Accident; Analysis and Prevention, 42(4), 1156-1163. https://doi. org/10.1016/j.aap.2010.01.004

Liang, S., Leng, H., Yuan, Q., Wang, B., \& Yuan, C. (2020). How does weather and climate affect pedestrian walking speed during cool and cold seasons in severely cold areas? Building and Environment, 175, 106811. https://doi.org/10.1016/j. buildenv.2020.106811

Methorst, R., Schepers, P., Christie, N., Dijst, M., Risser, R., Sauter, D., \& van Wee, B. (2017). 'Pedestrian falls' as necessary addition to the current definition of traffic crashes for improved public health policies. Journal of Transport \& Health, 6, 10-12. https://doi.org/10.1016/j.jth.2017.02.005

Möller, S., Wallman, C.-G., \& Gregersen, N. P. (2013). Vinterväghållning i tätort: Trafiksäkerhet och framkomlighet. Bilaga. Retrieved from TFB \& VTI forskning/research 2:1., Transportforskningsberedningen och Statens Väg-, och Trafikinstitut website: https://www.diva-portal.org/smash/ record.jsf?pid=diva2\%3A671979\&dswid $=4598$

Muraleetharan, T., Meguro, K., Adachi, T., Hagiwar, T., \& Kagaya, S.'i. (2005). Influence of Winter Road Conditions and Signal Delay on Pedestrian Route Choice in Japan's Snowiest Metropolis. Transportation Research Record: Journal of the Transportation Research Board, 1939, 145-153. https://doi. org/10.3141/1939-17
Niska, A. (2011). Cykelvägars standard : en

kunskapssammanställning med fokus på drift och underhåll: Service levels of cycleways -state-of-the-artreportfocusing on maintenance and operation. VTI Rapport 726.

Niska, A., \& Eriksson, J. (2013). Statistik över cyklisters olyckor: faktaunderlag till gemensam strategi för säker cykling: Cycling accident statistics. Background information to the common policy strategy for safe cycling. VTI Rapport 801.

Nyberg, P., Björnstig, U., \& Bygren, L. O. (1996). Road characteristics and bicycle accidents. Scandinavian Journal of Social Medicine, 24(4), 293-301. https://doi. org/10.1177/140349489602400410

Öberg, G., Nilsson, G., Velin, H., \& Wretling, P. (1996). Single accidents amongpedestrians and cyclists: Fotgängares och cyklisters singelolyckor. Linköping: VTI meddelande.

Parkin, L., Williams, S. M., \& Priest, P. (2009). Preventing winter falls: A randomised controlled trial of a novel intervention. The New Zealand Medical Journal, 122(1298), 31-38.

Phillips, D. (2010). Why Do We Bike Slower In The Cold Weather? Retrieved from http://fitwerx.com/why-do-we-bike-slower-inthe-cold-weather

Ruotsalainen, J., Ruuhela, R., \& Kanas, M. (2004). Preventing pedestrian slipping accidents with help of a weather and pavement condition model. Proceedings of Walk21-VCities for People, the Fifth International Conference on Walking in the 21st Century.

Schepers, P.; Brinker, B. d.; Methorst, R.; Helbich, M. (2017): Pedestrian falls: A review of the literature and future research directions. Journal of Safety Research 62, DOI: 10.1016/i. jsr.2017.06.020

Shintani, Y., Hara, F., Fukumoto, A., \& Akiyama, T. (2003). Empirical Study on Walking Behavior in Icy Conditions and Effect of Measures to Improve Winter Pedestrian Environment. Proceedings of TRB 82nd Annual Meeting.

Shirgaokar, M., \& Gillespie, D. (2016). Exploring User Perspectives to Increase Winter Bicycling Mode Share in Edmonton, Canada. Transportation Research Board 95th Annual MeetingTransportation Research Board. (16-2028UR https://trid.trb.org/view/1392739).

Wallqvist, V., Kjell, G., Cupina, E., Kraft, L., Deck, C., \& Willinger, R. (2017). New functional pavements for pedestrians and cyclists. Accident; Analysis and Prevention, 105, 52-63. https://doi.org/10.1016/j.aap.2016.04.032

Weidmann, U. (1992). Transporttechnik der Fussgänger: Transporttechnische Eigenschaften des Fussgängerverkehrs, Literaturauswertung. https://doi.org/10.3929/ ETHZ-A-000687810 